time, in other regions of the world (as in China), the dire need to provide more access to higher education and to increase the student population involves the same dilemmas that characterized the so-called massification elsewhere of how to square the circle between funding, structural adaptation, and quality of education.

\section{Shifting Demographics in Higher Education in Asia}

\section{Bie Dunrong}

Bie Dunrong is professor and deputy dean of the School of Education, at Huazhong University of Science and Technology. Address: Wuhan City, 430074, Hubei, China. E-mail:biedunrong@yahoo.com.cn.

$\mathrm{T}$ he Asian region is now going through a period of rapid and far-reaching economic and social changes, driven particularly by the impact of accelerating globalization, increased economic modernization, and transition toward a knowledgebased society. Higher education in the region has experienced decades of expansion in access that can be characterized as massification. The rapid growth of higher education has transformed higher education systems in many countries from elite to mass, placing colleges and universities under considerable strain regarding infrastructure, resources, and expertise.

Ongoing population growth in many developing countries of the region leads to a steady increase in the number of young people. At the same time, the demand for higher education continues to expand. In China, higher education enrollments rose from 6.4 million in 1998 to more than 23 million in 2005 , with the gross enrollment rate going from 9.8 to 2I percent of the relevant age cohort. Even in countries with well-developed higher education systems, increases in enrollments have been impressive. For example, enrollments in the Republic of Korea increased from $2,950,826$ to $3,500,560$ between 1998 and 200I. Among countries in the region, Japan is unique, for declining birthrates are a real concern for Japanese universities and colleges. The number of I8-year-olds in Japan is decreasing rapidly from year to year. In I99I, the age cohort was 2.05 million in size; it is predicted that the number will decline to I.2 million in 2009 , a drop of almost 40 percent in less than 20 years.

Also, the overall enrollment rates in higher education are still relatively low in many countries. While the region has some of the most prosperous countries in the world (Japan, South Korea, Singapore, and some of the west Asian nations), there are still a large number of developing countries, some are the poorest in the world (Cambodia, Laos, and Myanmar). In addition, gender disparities in higher education participation persist in the region, although female students outnumber male students in several countries in the region. Despite expansion in enrollments in recent years-especially for women, nonurban populations, and members of minority groups-access and participation remain a problem in the majority of countries in the region.

\section{Challenges}

Massification of higher education has and will continue to create a heavy financial burden on the public budget of most countries in the region. Governments and institutions of higher education in the region have to find sufficient resources to offer more and better-quality education to the potential consumers and cope with the needs of a rapidly developing information and knowledge society. For most Asian countries, a major dilemma in the development of higher education involves expanding participation in higher education while securing the quality of higher education at acceptable standards under the pressure of a shortage of resources.

The private sector plays a small but increasing role in some Asian countries, whereas in others private involvement is extensive. Over the past five years private colleges and universities in Malaysia increased in number from about too to 690 , while in Bangladesh almost Ioo new private higher education institutions were established between I998 and 200I. Over the same period, 46 new private institutions were founded in Mongolia and 20 in Nepal. In Kazakhstan, the number of private higher education institutions rose from 4I to I23 between I995 and 200I. In 200I, Vietnam had I7 private universities and 5 private colleges. In India, private higher education institutions now outnumber government institutions in a number of states. In Japan, South Korea, the Philippines, and

\section{In China, higher education enrollments rose from}

6.4 million in 1998 to more than 23 million in 2005 , with the gross enrollment rate going from 9.8 to 21 percent of the relevant age cohort.

Indonesia private universities enroll the majority of studentsin some cases up to 80 percent. Most Asian private universities serve the mass higher education market and tend to be relatively nonselective in their admissions.

As a world trend, internationalization greatly affects higher education in the region. The influence is revealed not only in the mobility of international students but also the operation and development of institutions of higher education. In the past decade, foreign education providers have begun to play an important role in Indian higher education. Malaysia has four branch campuses of foreign universities while many of the 690 private colleges have established overseas partnerships. Foreign as well as regional virtual and distance-education institutions are more frequently offering courses in Malaysia as well as in other parts of the region. Asia has long been the 
importer of international higher education, and thousands of students from Asian countries go to study in North America, Europe, and the Pacific every year.

\section{Strategies}

Though there is disparity in higher education among countries of the region, some common initiatives and strategies may be engaged in future development of higher education in most Asian countries. While governments face an ongoing public responsibility to ensure adequate funding of higher education institutions, it is recognized that diversified sources of support and funding may play an important role in the future development of higher education in the region. It may be a critical alternative for institutions of higher education to form alliances with industry in teaching and research. These alliances or industrialization of education may bring great mutual benefits in terms of equipment, professional practitioners, and cutting-edge ideas as well as a cheap source of a trainable workforce.

While the system of higher education is transforming from an elite to a massive one, the rapid expansion usually demands structural changes. In many countries of the region, adjustments need to be made within institutions, especially in access and admissions policies, course delivery, student learning strategies, and curriculum content, while in many cases national policy frameworks and overall planning approaches also need redirection. Quality and expansion has been a dilem-

\section{Massification of higher education has and will con-} tinue to create a heavy financial burden on the public budget of most countries in the region.

ma faced by many countries. New quality assurance mechanisms may be initiated to protect healthy and sustainable development of higher education in the developing countries of the region as the systems of higher education keep expanding. Cooperation between institutions may result in innovative joint ventures including twinning programs, consortia, exchange programs, joint ventures, and credit transferamong institutions of higher education in one country as well as between different countries_-offering more opportunities for students to move across national systems.

Many Asian countries have to develop their higher education systems on the basis of their own endeavors, but international assistance can play a very active and influential role. In fact, more international, multinational, and bilateral assistance to the systems of higher education in many countries of the region are required. An important source of funding for particular developing countries are loan funds from international agencies such as the World Bank, the Asian Development Bank, and so on, and aid programs from a variety of donor nations.

\section{CONCLUSION}

Rapid expansion of participation has been the major feature of higher education in Asia over the past decades. Adaptation to the massive higher education systems is under way in the region. Resource shortage constitutes the major obstacle faced by developing countries of the region. Innovations should be engaged in Asia to maintain the swift growth of access and acceptable quality of higher education in the future.

\section{Demographic Trends and Risks for European Higher Education}

\section{Fatma Mizikaci and Bernd Baumgartl}

Bernd Baumgartl is executive and principal of Navreme Knowledge Development and guest professor at European Peace University. Address: Margarettenstrasse 99, AT 1050 Vienna, Austria. E-mail: baumgartl@navreme.net. Fatma Mizikaci is program director of Navreme Knowledge Development and guest professor at Near East University, Cyprus. Address: Dede Korkut sok. 7/6, A. Ayranc_ Ankara Turkey. E-mail: mizikaci@navreme.net.

$\mathrm{D}$ emography plays a big role-with key policies of education determined by the composition of the population. The pace and dynamics of population growth are crucial to education planning. The size of the school-age population and hence the potential demand for education affect educational decisions. Furthermore, regional birthrates, migratory flows, and geographic distribution of population will directly impact the decisions of education cost, school types, school mapping, and academic staff recruitment. The distribution of the working population in terms of economic sector and levels of qualification determines the labor needs, thus designating the goals of higher education.

Population projections in the original 27 EU countries together with recently admitted member countries reveal the demographic impacts: data on birthrates, migration, and mobility will combine and coincide with a shrinking youth population over the next 50 years. In many countries the size of the elderly population is increasing faster than the birthrates. Populations in the EU-27 countries failed to reproduce themselves over a prolonged period with a lower than I.5 birthrate. European universities, which traditionally educate students aged I8-to-25 years, will obviously be affected from the reduced numbers of their traditional target group in the long term. It is projected that some higher education systems in Europe are under the high risk of closure or setback while 